\title{
Research Paper: Alexithymia and Personality Factors Among Students With and Without Autism Spectrum Disorder
}

Ebrahim Rahbar Karbasdehi ${ }^{* *}$, Abbas Abolghasemi' ${ }^{1}$ Fatemeh Rahbar Karbasdehi ${ }^{1}$

1. Department of Psychology, Faculty of Literature and Humanities, University of Guilan, Rasht, Iran.

Citation: Rahbar Karbasdehi E, Abolghasemi A, Rahbar Karbasdehi F. Alexithymia and Personality Factors Among Students With and Without Autism Spectrum Disorder. Iranian Rehabilitation Journal. 2018; 16(1):77-82. https://doi.org/10.29252/nrip.irj.16.1.77

https://doi.org/10.29252/nrip.irj.16.1.77

Article info:

Received: 10 May 2017

Accepted: 01 Oct. 2017

\section{Keywords:}

Affective symptoms, Personality, Autism spectrum disorder

\section{ABSTRACT}

Objectives: Autism Spectrum Disorder (ASD), is a group of neurodevelopmental disorders associated with -diverse communicative problems and Asperger's syndrome. The aim of this study was to compare alexithymia and personality factors in students with and without ASD.

Methods: In this study 120 male students with and without ASD were included. All the students were from Rasht city, studying in the academic year 2016-2017. The students were asked to take up Toronto Alexithymia Scale (TAS) and Big Five Questionnaire for Children (BFQ-C). Statistical comparison within the variables were carried out by Multivariate Analysis of Variance (MANOVA). The probability value less than 0.05 considered to be significant.

Results: The MANOVA of results showed a significantly higher mean scores of alexithymia components and neuroticism in the students with ASD. However, the mean scores of agreeableness, extraversion, openness to experience and conscientiousness were significantly lower in the students with ASD $(\mathrm{P}<0.001)$.

Discussion: The results garnered from this study implied that alexithymia and personality factors were significantly influenced by ASD. The findings of this research persuaded the pivotal implication of aforesaid facts on education and mental health of the students.

\section{Introduction}

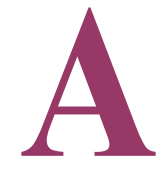

utism Spectrum Disorders (ASD) are severe neurodevelopmental disorders, characterized by impairments in social interaction, verbal and non-verbal communication, along with a restricted repertoire of activities and interests. This disorder is referred to as a "spectrum disorder" due to the heterogeneity of symptoms and symptom severity that individuals experience [1]. Males most likely gets affected by ASD compared to females, where the ration of ASD affected male to female are $6: 1[2,3]$

Furthermore, findings suggest that females with ASD gets diagnosed at a later stage in their life compared to

* Corresponding Author:

Ebrahim Rahbar Karbasdehi, MA

Address: Department of Psychology, Faculty of Literature and Humanities, University of Guilan, Rasht, Iran.

Tel: +98 (911) 8057926

E-mail: ebrahim.rahbar74@gmail.com 
male patients [4]. Many a times they do not even meet the diagnostic criteria, even having significant autism traits [5]. According to research findings, defect in emotion processing may might have been the root cause of ASD symptoms especially the social interaction [6]. There is yet ambiguity in understanding the underlying mechanisms of emotion recognition deficits in individuals having ASD [7].

Alexithymia is the inability to identify and describe one's emotional experience and related to poor interpersonal functioning [8]. It is characterized by impaired capacity to consciously experience emotions [9]. Around $10 \%$ of the general population thought be alexithymic [10]. Additionally, significant alexithymic traits were also found in individuals with ASD [11] and Schizophrenia [12],. These two disorders are associated with overlapping deficits in social cognition [13]. Alexithymia is also related to defect in social functions [14] and interpersonal problems in individuals with ASD [15].

In a meta-analysis on 48 studies, Uljarevic and Hamilton [16] reported that the individuals with ASD have problem in visual emotion recognition. Ketelaars et al. [17] have reported high alexithymia level in women with ASD. These type of women were found to have lower scores on visual emotion recognition. This study signified that the ability to identify emotions might help in improving the subtle emotions.

Personality traits associated with ASD and how individuals with ASD present as regards to react to five personality factors, has less been explored [18]. Schwartzman et al. [18] reported positive association ofneuroticism and negative association of extraversion, openness to experience, agreeableness, and conscientiousness, with severity of autism symptom. Austin [19] worked on 201 university students with ASD in United Kingdom, and found to know that intense neuroticism, extraversion, and low agreeableness are correlated with high scores in ASD. Similarly, Wakabayashi et al. [20] compared autistic traits with five factor model of personality, in sample of 320 Japanese university students and conformed that ASD correlate with extraversion and conscientiousness negatively, and neuroticism positively. In brief, many studies have conclusion that employing the five factor model of personality, represents an empirical approach to identify possible subtypes of ASD and developmental origins of these subtypes [18].

To our knowledge, earlier studies have emphasized the identification of characteristics in ASD children, and have not sufficiently discussed the psychological factors involved. Thus, attempts were made in the present study to compare alexithymia and personality factors in students with and without ASD.

\section{Methods}

Causal-comparative method was used in this study where alexithymia and five factors of personality in students with and without ASD were compared. One hundred and twenty high school male students, with and without ASD were taken from Rasht city for the study. The students were aged between 13 to 15 years. Sixty students with ASD were selected from Centre for Treatment of Austistic Disorder. And another group of 60 students without ASD were taken from a public school, Rasht city. The participants were selected by accessibility sampling technique.

The students with ASD followed inclusion criteria to meet the diagnostic criterion of ASD as per diagnostic and statistical manual of mental disorder- 5 published by American Psychiatric Association (2013). The whole process was carried out under the supervision of a licensed psychologist and the willingness of the participants were of highest concern. The students with ASD were admitted in a local private school where they were taught with typical curriculum.

The students received intensive instruction on social, behavioral, communication and functional skills. A multidisciplinary team comprised of educators, behavior analysts, psychologists, speech-language pathologists, and occupational therapists were responsible to design a comprehensive treatment plan for each child.

\section{Study design}

\section{Big Five Questionnaire for Children (BFQ-C)}

This questionnaire consisted of 65-items [21], primarily it was planned for the evaluation of five-factor of personality (extraversion, agreeableness, conscientiousness, neuroticism, openness to experience) among children and adults. The manner of giving response to the questions were through a 5-point Likert Scale (1: Almost never; to 5: Almost always) [21]. Cronbach's alpha coefficient for neuroticism of 0.87 , conscientiousness of 0.86 , extraversion of 0.84 , agreeableness of 0.89 , openness to experience of 0.86 , have been reported [22]. Correlation coefficient of sub-scales of extraversion, agreeableness, conscientiousness, neuroticism, openness to experience were analyzed with Pro-social Behavior Questionnaire (PBQ). The results were posi- 
tive and found to to be $\mathrm{r}=0.34, \mathrm{r}=0.58, \mathrm{r}=0.37, \mathrm{r}=0.55$, $\mathrm{r}=0.34$ respectively [23]. In Iran, cronbach's alpha coefficient for neuroticism, conscientiousness, extraversion, agreeableness, openness to experience, were found to be $0.74,0.78,0.65,0.72$ and 0.72 respectively. Correlation coefficient of subscales of extraversion, agreeableness, conscientiousness, neuroticism, openness to experience in this questionnaire with Eysenck Personality Questionnaire (EPQ) were reported to be positive [24].

\section{Toronto Alexithymia Scale (TAS)}

This scale consists of 20 items in the format of 5-point Likert Scale (1: Strongly disagree; to 5: Strongly agree). It measures three dimensions of the alexithymia construct like Difficulty Identifying Feelings (DIF), Difficulty Describing Feelings (DDF), and Externally Oriented Thinking (EOT) [25]. Cronbach's alpha coefficient of this scale was 0.75 . Correlation coefficient of subscales of difficulty identifying feelings, difficulty describing feelings, and externally oriented thinking in this scale along with Somatic Check List (SCL) were found to be $\mathrm{r}=0.48$, $\mathrm{r}=0.32$ and $\mathrm{r}=0.07$ respectively which were positive [26]. The results were In Iran, the Cronbach alpha coefficient of this scale was found to be 0.85 . The TAS-20's total score was negatively associated with Emotional Intelligence $(\mathrm{r}=-0.80)$. Psychological well-being was $\mathrm{r}=-0.78$ . The psychological well-being was positively associated with Psychological distress score $(\mathrm{r}=0.44)$. All three TAS-20 subscales were also significantly correlated with the Emotional Intelligence Scale-41 (EIS-41) and Mental Health Inventory (MHI) scores [27].

\section{Procedure}

The students with ASD were selected from the Center for the treatment of autistic disorders. Informed consents were taken from parents of participant children. The students without ASD were also selected from public school. The objectives of the research were explained to each of the participants and then the questionnaires were distributed mainly in two groups.

\section{Statistical analysis}

SPSS (Statistical Package for Social Sciences) 17.0 was used in the study. Significance test such as numerical and percentage values, Multivariate Analysis of Variance (MANOVA) was used in data analysis. $\mathrm{P}<0.05$ value was taken as level of significance.

\section{Results}

The mean standard deviation of age of students with and without ASD were $13.8 \pm 0.8$ and $14.1 \pm 0.8$ respectively with an average age of 13-15 years. In the ASD group $50 \%$ of the students were in the $7^{\text {th }}$ grade, $20 \%$ of the $8^{\text {th }}$ grade and $30 \%$ of the $9^{\text {th }}$ grade. In the group without ASD, $26.7 \%$ are in the $7^{\text {th }}$ grade, $33.3 \%$ in the $8^{\text {th }}$ grade and $40 \%$ in the $9^{\text {th }}$ grade. In the group with ASD, $30 \%$ are the first child, $40 \%$, the second child and $30 \%$, the third child, and in the group without ASD, $40 \%$ are the first child, $36.7 \%$, the second child and $23.3 \%$, the third child.

Before applying parametric multivariate analysis of variance, Box's and Levene's tests were used to observe its assumptions. According to Box's test, which was not meaningful for any of the variables, uniformity condition for variance/covariance matrices was observed correctly $(\mathrm{BOX}=15.76, \mathrm{~F}=2.23$ and $\mathrm{P}=0.11)$. Levene's test, was not meaningful for all the variables, equality condition for the group variances.

The results of Wilk's Lambda test showed the significant effect of the group on the combination of alexithymia components and factors of personality (Wilks'

Table 1. Mean and standard deviation of alexithymia and personality factors in the students with and without ASD

\begin{tabular}{|c|c|c|c|c|c|}
\hline \multirow{2}{*}{\multicolumn{2}{|c|}{ Variables }} & \multicolumn{2}{|c|}{ With ASD } & \multicolumn{2}{|c|}{ Without ASD } \\
\hline & & Mean & SD & Mean & SD \\
\hline \multirow{3}{*}{ Alexithymia } & Difficulty identifying feelings & 12.13 & 2.16 & 10.73 & 2.91 \\
\hline & Difficulty describing feelings & 11.40 & 2.19 & 9.76 & 1.88 \\
\hline & Externally oriented thinking & 17.46 & 1.61 & 12.86 & 2.99 \\
\hline \multirow{5}{*}{ Five factors of personality } & Agreeableness & 28.23 & 5.36 & 48.60 & 2.98 \\
\hline & Neuroticism & 43.90 & 5.52 & 36.96 & 6.95 \\
\hline & Extraversion & 29.64 & 4.87 & 55.20 & 4.21 \\
\hline & Openness to experience & 31.06 & 7.54 & 53.50 & 2.02 \\
\hline & Conscientiousness & 27.30 & 6.81 & 46.80 & 3.60 \\
\hline
\end{tabular}

Ilranian Rehabilitation Journal 
Table 2. Results of the analysis of multivariate varianceof alexithymia and personality factors in the students with and without ASD

\begin{tabular}{lccccccc}
\hline & Variable & SS & df & MS & F & P & Eta \\
\hline \multirow{3}{*}{ Alexithymia } & Difficulty identifying feelings & 29.40 & 1 & 29.40 & 4.47 & 0.039 & 0.072 \\
& Difficulty describing feelings & 40.01 & 1 & 40.01 & 9.56 & 0.003 & 0.142 \\
& Externally oriented thinking & 317.40 & 1 & 317.40 & 54.96 & 0.001 & 0.487 \\
& Agreeableness & 6222.01 & 1 & 6222.01 & 329.69 & 0.001 & 0.850 \\
\multirow{2}{*}{ Five factors of personality } & Neuroticism & 721.06 & 1 & 721.06 & 18.29 & 0.001 & 0.240 \\
& Extraversion & 9933.06 & 1 & 9933.06 & 478.39 & 0.001 & 0.892 \\
& Openness to experience & 7548.81 & 1 & 7548.81 & 228.35 & 0.001 & 0.797 \\
& Conscientiousness & 5703.75 & 1 & 5703.75 & 191.76 & 0.001 & 0.768 \\
\hline
\end{tabular}

Iranian Rehabilitation Journal

Lambda $=0.095, \mathrm{~F}=1.02, \mathrm{P}<0.001$ and $\mathrm{Eta}=0.905)$. The test mentioned above permitted the usability of Multivariate Analysis of Variance (MANOVA).

The results obtained from the MANOVA showed the means of difficulty identifying feelings $(\mathrm{F}=4.47)$, difficulty describing feelings $(\mathrm{F}=9.56)$ and externally oriented thinking $(\mathrm{F}=54.96)$ scores were significantly higher in the students with ASD. The mean of neuroticism $(\mathrm{F}=18.29)$ score was significantly higher in the students with ASD and the means of agreeableness $(\mathrm{F}=329.69)$, extraversion $(\mathrm{F}=478.39)$, openness to experience $(\mathrm{F}=228.35)$, conscientiousness $(\mathrm{F}=191.76)$ scores were significantly lower in the students with ASD $(\mathrm{P}<0.001)$ (Table 2).

\section{Discussion}

The aim of this research was to compare alexithymia and personality factors in students with and without ASD. The results of the present research showed that student with ASD had higher alexithymia than student without ASD $(\mathrm{P}<0.001)$. The result of this study coincided with previous studies $[16,17]$. Alexithymia is marked by the low ability to experience, name, and express emotions of anybody. Alexithymic individuals with ASD cannot express their emotions or distinguish the emotions from the face. They do not have the sympathy for others, and have problem in their communication with others [15]. Alexithymia is challenging for individuals with ASD as they lack of imagination and emotion [28]. ASD individuals with high level of alexithymia needs more attention towards their physical sensitivity rather than psychiatric problems [29].
The results of this study made us to know that the student with ASD have lower agreeableness, extraversion, openness to experience and conscientiousness than student without ASD. The students with ASD have higher neuroticism than student without ASD $(\mathrm{P}<0.001)$. This result coincided with the previous studies $[18,19]$. Low extraversion in individuals with ASD were influenced soon by environmental motives and they preferred to be alone for a long time and go inside themselves [30]. These individuals also have lesser tendency to experience positive emotions and experience less rewards in social situations [31].

It has been hypothesized that individuals with ASD, compared to individuals without ASD, exhibit reduced social interest or decreased responsivity to social reward [32]. The finding that agreeableness in individuals with ASD is less than regular individuals. This can be explained based on the point that decrease in the feeling of cooperation, altruism, patience and flexibility in individuals with ASD may be an important factor for intensifying the symptoms specially decrease of social interests. Individuals with low self-efficacy are described as feeling incompetent and not in control their own lives [30]. Individuals with ASD are often described as individuals having impulsive action [11].

Individuals with ASD experience low openness. The difficulty in accepting the norms and rules of the society lead to emotional trauma in ASD patients. The inability to express the weakness openly lead to lack of innovation tendency and creativity, lack of readiness for acceptance of other's ideas and lack of expressing emotions [33]. consequently, it causes disorder in behavior and emotions [30] and Low conscientiousness in individu- 
als with ASD indicate that this as a preventing variable, can prevent psychiatric trauma. Conscientiousness gets identified with some specifications such as discipline, conscience, responsibility, tendency to progress, caution, honesty, good greeting and continence.

Therefore, the individuals with ASD obey lesser rules and regulations, and cannot respect others' rights [34]. Furthermore, higher neuroticism in individuals with ASD use to have anxiety, depression, irritability, aggression, impulsivity, pride, egotism and vindictiveness. Therefore, these individuals have less emotional and behavioral adaptation and easily get aggressive and failure feeling. Neuroticism causes the experience of distress and negative emotions such as anxiety, anger and depression in individuals with ASD [35]. Limitations of the current study relate primarily to the nature of our sample, which was relatively small and male individuals. Although these characteristics are not unusual for causal-comparative studies of ASD utilizing psychophysiological measures, they limit our ability to generalize our resuts to a larger ASD sample with equal gender ratio.

\section{Conclusion}

The present study has important implications in the field of pathology of this disorder. In the practical level (clinical), preparation of treatment plans based on recognition and emotional processing can be effective in treating the people with ASD.

\section{Acknowledgments}

This research did not receive any specific grant from funding agencies in public, commercial, or non-profitable organization. The authors would like to thank all the participants and their families who patiently participated in our study.

\section{Conflict of Interest}

The authors declared no conflicts of interest.

\section{References}

[1] American Psychiatric Association. Diagnostic and statistical manual of mental disorders (DSM-5®). Washington, D.C.: American Psychiatric Association; 2013.
[2] Fombonne E. The epidemiology of autism: A review. Psychological Medicine. 1999; 29(4):769-86. Available from: http://dx.doi.org/10.1017/s0033291799008508

[3] Kirkovski M, Enticott PG, Fitzgerald PB. A review of the role of female gender in autism spectrum disorders. Journal of Autism and Developmental Disorders. 2013; 43(11):2584-603. Available from: http://dx.doi.org/10.1007/s10803-013-1811-1

[4] Begeer S, Mandell D, Wijnker Holmes B, Venderbosch S, Rem D, Stekelenburg F, et al. Sex differences in the timing of identification among children and adults with autism spectrum disorders. Journal of Autism and Developmental Disorders. 2012; 43(5):1151-6. Available from: http://dx.doi org/10.1007/s10803-012-1656-Z

[5] Dworzynski K, Ronald A, Bolton P, Happé F. How different are girls and boys above and below the diagnostic threshold for autism spectrum disorders?. Journal of the American Academy of Child \& Adolescent Psychiatry. 2012; 51(8):788-97. Available from: http://dx.doi.org/10.1016/j. jaac.2012.05.018

[6] Humphreys K, Minshew N, Leonard GL, Behrmann M. A fine-grained analysis of facial expression processing in highfunctioning adults with autism. Neuropsychologia. 2007; 45(4):685-95. Available from: http://dx.doi.org/10.1016/j. neuropsychologia.2006.08.003

[7] Bird G, Cook R. Mixed emotions: The contribution of alexithymia to the emotional symptoms of autism. Translational Psychiatry. 2013; 3(7):e285. Available from: http://dx.doi. org/10.1038/tp.2013.61

[8] Aaron RV, Benson TL, Park S. Investigating the role of alexithymia on the empathic deficits found in schizotypy and autism spectrum traits. Personality and Individual Differences. 2015; 77:215-20. Available from: http://dx.doi.org/10.1016/j. paid.2014.12.032

[9] Lane RD, Ahern GL, Schwartz GE, Kaszniak AW. Is alexithymia the emotional equivalent of blindsight. Biological Psychiatry. 1997; 42(9):834-44. Available from: http:/ /dx.doi org/10.1016/s0006-3223(97)00050-4

[10] Salminen JK, Saarijärvi S, Äärelä E, Toikka T, Kauhanen J. Prevalence of alexithymia and its association with sociodemographic variables in the general population of finland. Journal of Psychosomatic Research. 1999; 46(1):75-82. Available from: http:/ /dx.doi.org/10.1016/s0022-3999(98)00053-1

[11] Hill EL. Executive dysfunction in autism. Trends in Cognitive Sciences. 2004; 8(1):26-32. Available from: http://dx.doi. org/10.1016/j.tics.2003.11.003

[12] Van't Wout M, Aleman A, Bermond B, Kahn RS. No words for feelings: Alexithymia in schizophrenia patients and first-degree relatives. Comprehensive Psychiatry. 2007; 48(1):27-33. Available from: http://dx.doi.org/10.1016/j. comppsych.2006.07.003

[13] Sasson NJ, Pinkham AE, Carpenter KLH, Belger A. The benefit of directly comparing autism and schizophrenia for revealing mechanisms of social cognitive impairment. Journal of Neurodevelopmental Disorders. 2010; 3(2):87-100. Available from: http:/ /dx.doi.org/10.1007/s11689-010-9068-x

[14] Insel T, Cuthbert B, Garvey M, Heinssen R, Pine DS, Quinn $\mathrm{K}$, et al. Research Domain Criteria (RDoC): Toward a new classification framework for research on mental disorders. 
American Journal of Psychiatry. 2010; 167(7):748-51. Available from: http:/ / dx.doi.org/10.1176/appi.ajp.2010.09091379

[15] Koven NS. Abnormal valence differentiation in alexithymia. Personality and Individual Differences. 2014; 68:102-6. Available from: http://dx.doi.org/10.1016/j.paid.2014.04.007

[16] Uljarevic M, Hamilton A. Recognition of emotions in autism: A formal meta-analysis. Journal of Autism and Developmental Disorders. 2012; 43(7):1517-26. Available from http://dx.doi.org/10.1007/s10803-012-1695-5

[17] Ketelaars MP, In't Velt A, Mol A, Swaab H, van Rijn S. Emotion recognition and alexithymia in high functioning females with autism spectrum disorder. Research in Autism Spectrum Disorders. 2016; 21:51-60. Available from: http:// dx.doi.org/10.1016/j.rasd.2015.09.006

[18] Schwartzman BC, Wood JJ, Kapp SK. Can the five factor model of personality account for the variability of autism symptom expression? Multivariate approaches to behavioral phenotyping in adult autism spectrum disorder. Journal of Autism and Developmental Disorders. 2015; 46(1):253-72. Available from: http://dx.doi.org/10.1007/s10803-0152571-x

[19] Austin EJ. Personality correlates of the broader autism phenotype as assessed by the Autism Spectrum Quotient (AQ) Personality and Individual Differences. 2005; 38(2):451-60. Available from: http://dx.doi.org/10.1016/j.paid.2004.04.022

[20] Wakabayashi A, Baron Cohen S, Wheelwright S. Are autistic traits an independent personality dimension? A study of the Autism-Spectrum Quotient (AQ) and the NEO-PI-R. Personality and Individual Differences. 2006; 41(5):873-83. Available from: http://dx.doi.org/10.1016/j.paid.2006.04.003

[21] Barbaranelli C, Caprara GV, Rabasca A, Pastorelli C. A questionnaire for measuring the Big Five in late childhood. Personality and Individual Differences. 2003; 34(4):64564. Available from: http://dx.doi.org/10.1016/s0191 8869(02)00051-x

[22] Maćkiewicz M, Cieciuch J. Pictorial Personality Traits Questionnaire for Children (PPTQ-C): A new measure of children's personality traits. Frontiers in Psychology. 2016; 7:498 Available from: http://dx.doi.org/10.3389/fpsyg.2016.00498

[23] Barbaranelli C, Caprara GV, Rabasca A, Pastorelli C. A questionnaire for measuring the Big Five in late childhood. Personality and Individual Differences. 2003; 34(4):64564. Available from: https://doi.org/10.1016/S01918869(02)00051-X

[24] Yousefi R, Molla Alizade M. [The adaptation and standardization of Big Five Personality Questionnaire for Children (BFQ-C) in high school students (Persian)]. Journal of New Thoughts on Education. 2015; 10(3): 123-38. doi: 10.22051/ jontoe.2015.379

[25] Bagby RM, Parker JDA, Taylor GJ. The twenty-item Toronto Alexithymia scale-I: Item selection and cross-validation of the factor structure. Journal of Psychosomatic Research. 1994; 38(1):23-32. Available from: http:/ / dx.doi.org/10.1016/00223999(94)90005-1

[26] Rieffe C, Oosterveld P, Terwogt MM. An alexithymia questionnaire for children: Factorial and concurrent validation results. Personality and Individual Differences. 2006; 40(1):123-33. Available from: http://dx.doi.org/10.1016/j. paid.2005.05.013
[27] Besharat MA. Reliability and factorial validity of a Farsi version of the 20-item Toronto Alexithymia Scale with a sample of Iranian students. Psychological Report. 2007; 101(5):209. Available from: http:/ / dx.doi.org/10.2466/ pr0.101.5.209-220

[28] Meijer Degen F, Lansen J. Alexithymia: A challenge to art therapy. The Arts in Psychotherapy. 2006; 33(3):167-79 Available from: http://dx.doi.org/10.1016/j.aip.2005.10.002

[29] Kellner R. Somatization. Journal of Nervous and Mental Disease. 1990; 178(3):150-60. Available from: http://dx.doi. org/10.1097/00005053-199003000-00002

[30] Goldberg LR, Johnson JA, Eber HW, Hogan R, Ashton MC, Cloninger CR, et al. The international personality item pool and the future of public-domain personality measures. Journal of Research in Personality. 2006; 40(1):84-96. Available from: http://dx.doi.org/10.1016/j.jrp.2005.08.007

[31] DeYoung CG, Quilty LC, Peterson JB. Between facets and domains: 10 aspects of the Big Five. Journal of Personality and Social Psychology. 2007; 93(5):880-96. Available from: http:// dx.doi.org/10.1037/0022-3514.93.5.880

[32] Scott Van Zeeland AA, Dapretto M, Ghahremani DG, Poldrack RA, Bookheimer SY. Reward processing in autism. Autism Research. 2010; 3(2):53-67. doi: 10.1002/aur.122

[33] Silani G, Bird G, Brindley R, Singer T, Frith C, Frith U. Levels of emotional awareness and autism: An fMRI study. Social Neuroscience. 2008; 3(2):97-112. Available from: http:// dx.doi.org/10.1080/17470910701577020

[34] Barger B, Campbell J, Simmons C. Measuring five factor personality traits in autism during early childhood. Journal of Developmental and Physical Disabilities. 2014; 26(6):775-92. Available from: http:/ /dx.doi.org/10.1007/s10882-014-9392-2

[35] Montebarocci O, Codispoti M, Baldaro B, Rossi N. Adult attachment style and alexithymia. Personality and Individual Differences. 2004; 36(3):499-507. Available from: http:/ / dx.doi.org/10.1016/s0191-8869(03)00110-7 